jcrpe-2018-0213.R2

Original Article

\title{
Elevated Random Luteinizing Hormone Is Unreliable Indicator for Pubertal Suppression in Girls Treated with Monthly Leuprolide for Idiopathic Central Precocious Puberty
}

Short title: Random LH Levels in Central Precocious Puberty

${ }^{1}$ Pattara Wiromrat and ${ }^{1}$ Ouyporn Panamonta

${ }^{1}$ Division of Endocrinology, Department of Pediatrics, Faculty of Medicine, Khon Kaen University, Khon Kaen, Thailand 40002

\begin{abstract}
Objective: Longitudinal data in random luteinizing hormone (LH) concentrations in patients with idiopathic central precocious puberty (ICPP) during treatment are limited. Therefore, we sought to evaluate random LH and estradiol concentrations during monthly leuprolide injection and its associations with pubertal progression and final adult height (FAH) in girls with ICPP.

Methods: Medical records of 27 ICPP girls who attained FAH were reviewed. Patients' height, weight, Tanner stage, growth rate (GR), bone age, random LH, follicular-stimulating hormone (FSH) and estradiol were monitored until FAH.

Results: Treatment was started at mean $( \pm \mathrm{SD})$ age of $8.1 \pm 0.6$ years with duration of $3.9 \pm 0.2$ years. At 6 months of follow-up, random LH $(p=0.048)$, FSH $(p<0.001)$ and estradiol $(p=0.023)$ were significantly decreased from baseline. Thereafter, random LHs were well suppressed. GR was gradually declined to a prepubertal norm at month 12 . Seventeen patients $(63 \%)$ exhibited pubertal LH at least once at some points of treatment. Further, 43 of $116(37 \%) \mathrm{LH}$ measurements were in pubertal range; 0.6-2.9 (immunoradiometric assays) and 0.3-0.83 IU/L (immunochemiluminescent assay). However, no patients showed signs of pubertal progression during pubertal LH episodes. After treatment, the patients attained FAH that higher than predicted adult height $(\mathrm{p}<0.0001)$ and target height ( $p=0.03$ ). Random LH, FSH and estradiol at any time points did not correlate with GR nor FAH.

Conclusion: Elevated random LH is commonly found in ICPP girls during monthly leuprolide treatment. However, it does not associate with clinical progression of puberty nor decreased FAH suggesting that it is not a reliable method for CPP monitoring.

Key words: Central Precocious Puberty, Final Adult Height, Leuprolide acetate, Monitoring, Pubertal Progression, Random Luteinizing Hormone
\end{abstract}

What is already known on this topic?

To date, there has been no consensus method for biochemical monitoring for central precocious puberty (CPP). Previous studies have shown that girls with CPP commonly have pubertal LH on random measurement, particularly in whom treated with long-acting GnRH analog implant. However, data in girls treated with monthly leuprolide acetate are limited. Moreover, there has been no study showing random $\mathrm{LH}$ as well as its association with growth rates and final adult height in a longitudinal fashion.

\section{What this study adds?}

This study demonstrated that random LH is found elevated in $\sim 60 \%$ of CPP girls treated with monthly leuprolide with a magnitude of rising LH higher than previously reported. Despite elevated, random LH is not associated with pubertal progression, increased growth rates nor decreased final adult height suggesting that it is not a reliable method for ICPP monitoring.

\section{Corresponding author:}

Pattara Wiromrat, M.D., Clinical Instructor

Division of Endocrinology, Department of Pediatrics, Faculty of Medicine, Khon Kaen University, Khon Kaen, Thailand 40002 
Phone: +664-336-3012

E-mail: patwiro@kku.ac.th

Received: $\quad 31.08 .2018$

Accepted: $\quad 25.12 .2018$

\section{Introduction}

Idiopathic central precocious puberty (ICPP) is one of the most common endocrine disorder in girls. Gonadotropin-releasing hormone analog $(\mathrm{GnRHa})$ is the mainstay of therapy for pubertal suppression. This treatment also improves final adult height $(\mathrm{FAH})$ and reduces negative psychosocial consequences (1-4). However, the biochemical monitoring for ICPP treatment remains challenging since there has been no solid data demonstrating a universal cut-off levels of random or stimulated LH for defining pubertal suppression $(1,5-7)$. Moreover, the association between a lack of biochemical suppression with a clinical progression and its influence on growth rates (GR) or FAH have not been evaluated.

To date, suppressed stimulated LH has been widely used in several previous research to determine treatment efficacy in ICPP $(5,8,9)$. Nevertheless, some hospitals including ours have employed random (basal/unstimulated) LH for treatment monitoring because this approach is less invasive, less time-consuming and more convenient for resource-limited setting $(7,10)$. Few short-term studies $(10$, 11) have shown that random LH was commonly found elevated during 3-monthly and yearly formulations of GnRHa treatment. However, this data in a monthly preparation of leuprolide treatment are limited (8). Further, longitudinal data of this monitoring to better understand the changes of random LH over time are needed. Therefore, we sought to longitudinally assess the serum concentrations of random $\mathrm{LH}$, follicular stimulating hormone (FSH) and estradiol during monthly leuprolide injection and to assess its associations with pubertal progression and FAH in girls with ICPP.

\section{Materials and methods}

\section{Patients}

This study protocol was approved by the Khon Kaen University Ethical Committee (approval number; HE591411). Since this study is a retrospective study and our patient data were deidentified, the informed consent is not required by our Ethical Committee. During January 2002 to December 2016, 420 girls were referred for precocious puberty evaluation at our Pediatric Endocrine Clinic, Khon Kaen University Hospital. The Inclusion criteria were: 1) breast development (Tanner stage $\geq 2$ ) under the age of 8 years; 2) advanced bone age (BA) $\geq 1$ year; 3) GnRHa-stimulated LH $\geq 6.9$ IU/L $(12-14)$; 4) normal brain and pituitary magnetic resonance imaging; 5) received monthly GnRHa treatment.

There were 142 girls diagnosed as ICPP. A hundred and ten girls received monthly GnRHa treatment. Forty-seven girls reached FAH with complete medical records. Of these, 20 girls were excluded due to markedly advance BA ( $\geq 13$ years) "at the time of presentation", as this bone age represents $\sim 95 \%$ of FAH, and increased random LH concentrations may have less effect on the final height compared to the less matured bone. Therefore, there were 27 girls included in the analysis.

\section{Treatment}

Treatment was started in patients with 1) rapid progression, 2) markedly advanced BA $\geq 2$ years, or 3 ) differences in predicted adult height $(\mathrm{PAH})$ and target height $(\mathrm{TH})$ of $\geq 1.5$ SDS at initial or during follow-up. All patients received a monthly $3.75 \mathrm{mg}$ depot leuprolide acetate injection until the chronological age of 12 years. During treatment, no patients showed any clinical markers of pubertal progression (a change in breast Tanner stage, increased GR or vaginal bleeding), therefore, none received treatment modification.

\section{Follow up examination and hormonal measurement}

Height, weight and Tanner stage of breast and pubic hair were assessed every 3-6 months until the patients attained FAH. Height was measured to the nearest $0.1 \mathrm{~cm}$ using a stadiometer; weight was measured to the nearest $0.1 \mathrm{~kg}$. GR was calculated as changes in height during a 1-year interval. BA was assessed at the initial visit and before treatment discontinuation. Pretreatment PAH was estimated using the accelerated table of the Bayley and Pinneau method (15). All clinical parameters were 
assessed by the same pediatric endocrinologist. FAH was defined by $\mathrm{GR} \leq 0.5 \mathrm{~cm} /$ year or BA $\geq 16$ years.

Morning blood samples for serum random (basal) LH, follicular-stimulating hormone (FSH) and estradiol were collected at 7-8 AM before the regular scheduled leuprolide injection every 3-6 months at the pediatric endocrine clinic in the first year of treatment, and then at every 6 or 12 months if no clinical progression. During 2002-2013, serum LH and FSH were measured using highly sensitive IRMA (RIA-gnost ${ }^{\circledR}$, monoclonal mouse antibodies, hLH and $\mathrm{hFSH}$; CIS Bio International, Gif-SurYvette, France) with a lower detection limit of 0.1 and $0.15 \mathrm{IU} / \mathrm{L}$ with inter-assay coefficient variations of $9.4 \%$ and $8.7 \%$, respectively. After 2011, LH and FSH were analyzed using a more sensitive immunochemiluminescent assay or ICMA (Esoterix Laboratories (Calabasas Hills, CA, USA) with a detection limit of $0.02 \mathrm{IU} / \mathrm{L}$ for both hormones and inter-assay coefficient variations were $10.7 \%$ for LH and were $9.0 \%$ for FSH. In summary, there were $27 / 27,25 / 25,25 / 25,17 / 22$ and 9/17 random LH levels were analyzed using IRMA at 6, 12, 24, 36 and 48 months of treatment time points. Estradiol levels were measured by an ICMA (Immulite 2000, Siemens Medical Solutions Diagnostics, Los Angeles, CA, USA) with a detection limit of $5 \mathrm{pg} / \mathrm{mL}$. Hormonal values falling below the lower detection levels were taken as the lower detection levels. The random pubertal LH concentrations were defined as $\geq 0.6 \mathrm{IU} / \mathrm{L}$ for IRMA $(12,13)$ and $\geq 0.3 \mathrm{IU} / \mathrm{L}$ for ICMA $(10)$.

\section{Statistical analysis}

Statistical analysis was performed using SPSS 18. Data were presented as number, percentages, mean $\pm \mathrm{SD}$ and median (Q1, Q3) as proper. A T-test, paired t test or Chi-square test were used to test the differences between groups. Repeated measures ANOVA or mixed effect model was performed to compare two repeated measurements in the same individuals. Correlations were evaluated using Pearson correlation coefficients. Nonparametric tests were used in non-normally distributed data. Pvalue $<0.05$ was considered significance.

\section{Results}

\section{Patient characteristics}

Baseline patient characteristics are shown in Table 1. Patients reported their mean $( \pm \mathrm{SD})$ age of onset at $6.9 \pm 0.1$ years, however, treatment was started at mean age of $8.1 \pm 0.2$ years with a mean duration of $3.9 \pm 0.2$ years. All patients reported good treatment compliance, and none had missed or delayed the scheduled leuprolide injection. The reason for a delay in treatment initiation was mainly due to lack of knowledge about their disease. As expected, the patients had typical features of ICPP including breast development, tall stature, advanced BA and elevated random or stimulated LH concentrations.

\section{Growth rates and Final adult height}

Mean GR \pm SD at pretreatment and 6, 12, 24, 36 and 48 months during treatment were $8.5 \pm 2.5,6 \pm$ $1.2,5.6 \pm 1.1,4.1 \pm 1.5,4.1 \pm 1.3$ and $2.6 \pm 1.4 \mathrm{~cm} /$ year, respectively. After treatment, mean FAH was higher than initial PAH $(\mathrm{p}<0.0001)$ and $\mathrm{TH}(\mathrm{p}=0.03$, Table 2).

\section{Serum LH, FSH and estradiol concentrations}

Figure 1 shows random LH and estradiol concentrations during treatment. At 6 months of follow-up, the median serum LH $[1.7(0.3,3.5)$ vs $0.46(0.02,1.14)$; $=0.048]$, FSH $[4.2(2.6,5.8)$ vs $1.6(1.3$, $2.1) \mathrm{IU} / \mathrm{L} ; \mathrm{p}<0.001)$ and estradiol $[36(11,53)$ vs $9(4,12) ; \mathrm{p}=0.023)]$ significantly declined from pretreatment concentrations. Thereafter, the overall LH concentrations remained suppressed and tended to rise again at 36 and 48 months of follow-up. The median $(\mathrm{Q} 1, \mathrm{Q} 3)$ random LHs were 0.4 $(0.1,1.02)$ at 6 months, $0.11(0.1,0.64)$ at 12 months, $0.24(0.1,0.62)$ at 24 months, $0.34(0.07,0.82)$ for IRMA and $0.2(0.09,0.52)$ for ICMA at 36 months and $0.6(0.22,0.85)$ for IRMA and $0.24(0.23$, $0.61)$ for ICMA at 48 months of treatment. Median FSHs were $1.6(0.82,2.7), 1.8(1.2,2.6), 1.6(1.2$, $2.5), 1.4(0.6,1.7)$ and $0.6(0.54,1.7)$ at $12,24,36$ and 48 months of treatment, respectively. During treatment, $37 \%$ of a total $116 \mathrm{LH}$ measurements were in pubertal range $(\geq 0.6 \mathrm{IU} / \mathrm{L}$ for IRMA and $\geq 0.3 \mathrm{IU} / \mathrm{L}$ for ICMA). Among these, 10/27 (37\%), 7/25 (30\%), 7/25 (28\%), 9/22 (41\%) and 10/17 $(61 \%)$ of the patients had elevated random LH at month 6 (range, 0.85-2.92 IU/L), month 12 (range, 0.6-1.8 IU/L), month 24 (range, 0.61-1.8 IU/L), month 36 (range: $0.30-0.60 \mathrm{IU} / \mathrm{L}$ for ICMA and 0.60$2.5 \mathrm{IU} / \mathrm{L}$ for IRMA) and month 48 (range: $0.3-0.83$ for ICMA and $0.6-2$ IU/L for IRMA), respectively. Moreover, 17 out of 27 individuals (63\%) exhibited pubertal LH at least once at some points of treatment. However, these patients showed no signs of pubertal progression, therefore, none 
received treatment modification. Of a total 112 estradiol measurements, $29 \%$ were above the lower detection limit $(5 \mathrm{pg} / \mathrm{mL})$. However, all values were in prepubertal range of $<20 \mathrm{pg} / \mathrm{mL}$ (16) throughout the treatment duration.

\section{Correlation}

Random LH at any time points did not correlate with GR (Table 3) nor FAH (data not shown). Also, there were no correlation between random LH, FSHs, estradiol and BMI during treatment (data not shown). Neither FSH nor estradiol correlated with BMI, GR and FAH (data not shown).

\section{Patients with frequently elevated random $\mathrm{LH}$}

Table 4 shows the clinical characteristics of 3 patients who presented with markedly advanced BA (BA-CA 4.7-5.6 years), compromised PAH and frequently elevations in random LH during treatment. However, they did not show any signs of pubertal advancement. Finally, they attained FAHs which were higher than their PAH without any therapeutic modification.

\section{Discussion}

Monitoring patients with CPP is a clinical challenge since there is no consensus method for monitoring and failure of detection of HPG-axis suppression can cause a reduction in FAH (1). In this study, we demonstrated longitudinal serum random LH concentrations during treatment and its relationship with pubertal progression and FAH.

Our study demonstrated that random LH was elevated in 37\% of total measurements in ICPP patients during monthly leuprolide treatment with the magnitude of rising as high as $2.9 \mathrm{IU} / \mathrm{L}$ for IRMA and $0.62 \mathrm{IU} / \mathrm{L}$ for ICMA. Moreover, two-thirds of our patients exhibited pubertal LH levels at least once at some follow-up time points and approximately $30-60 \%$ of patients had random pubertal LH in each year of treatment. Yet, none had pubertal progression from clinical examination. There are only 3 studies evaluating random LH concentrations or prevalence of increased random LH in CPP patients during GnRHa treatment as a main outcome [one study in patients with trimonthly GnRHa injection (7) and 2 studies in patients receiving yearly GnRHa implant $(10,11)]$ and our number of patients with random pubertal LH is similar to those studies. Several findings in random LH concentrations in ICPP patients during various forms of GnRH treatment were reported $(5,8,10,11,17)$. Neely et al. (8) found that their subjects treated with a higher dose $(7.5-15 \mathrm{mg}$ ) of monthly leuprolide had well clinical and biochemical (random LH) suppression. Their patients' maximal random LH concentrations in each follow-up visit were also lower than what was found in our patients (IFMA; $0.5-0.8 \mathrm{IU} / \mathrm{L}$ vs $1.8-2.9 \mathrm{IU} / \mathrm{L})$. However, our patients were treated with a relatively lower dose of leuprolide $(3.75 \mathrm{mg}, 90-140 \mu \mathrm{g} / \mathrm{kg}$ ) which is a commonly reported dose in most Asian countries (18, 19). Elevated random LH was also commonly reported in 50-60\% of ICPP patients treated with histrelin implant, without patients showing sign of pubertal progression $(10,11)$. These patients also had stimulated LHs well suppressed in prepubertal norm. Similar findings were also demonstrated in a study using monthly leuprolide(20) and another study using 3-monthly leuprolide (17). In contrast, Brito et al.(5) found differently that 2 out of 18 patients had pubertal breakthrough (no specific report regarding "pubertal progression") which was confirmed by a modestly increase in random (0.9-1.1 IU/L, IFMA) and stimulated LH (4.3-5.7 IU/L). Therefore, these data indicated that elevated random LH is an unreliable marker for pubertal suppression. Several studies have shown the correlation between random (basal) and stimulated LH concentrations including Lee and colleagues' which is the only work that suggested the random (basal) LH cut-off value in a 36-month trimonthly leuprolide randomized trial. This study showed that basal LH (ICMA) $\geq 0.6 \mathrm{IU} / \mathrm{L}$ had an optimal $80 \%$ sensitivity and $70 \%$ specificity for predicting stimulated LH levels of $>4 \mathrm{IU} / \mathrm{L}$ (7). Again, this study did not demonstrate the relationship between increased basal LH or increased stimulated LH with clinical parameters such as bone age or clinical progression.

Our data also demonstrated that elevated random LH was not associated with GR nor FAH. There is only one study (21) showing similar result of no relationship between random LH and GR. That study also found that random LH had a negative association with the changes in PAH $(r=-0.309 ; p<0.05)$, assessed by regular BA examination. To our knowledge, there have been no studies demonstrating the association between either random or stimulated LH and FAH so far. Our study showed that random was not correlated to FAH. Although two third of patients experienced pubertal $\mathrm{LH}$, their overall FAH was above PAH and within upper range of TH. The FAH and height gain in our patients were also comparable to other studies with a report of well stimulated LH suppression in Thailand $(19,22)$ and other countries $(6,18,23)$. Moreover, albeit a small number, our three patients with frequently 
elevated random LH did not have any signs of pubertal progression, and eventually attained FAHs which was higher than their PAHs and THs without treatment modification. Taken together, our results indicated that elevated random $\mathrm{LH}$, in the context of no clinical progression being observed, may not have a negative effect on FAH.

Whereas average estradiol concentrations were prepubertal $(<20 \mathrm{pg} / \mathrm{mL})$, the number of detectable values ( $29 \%$ vs $12-25 \%$ of total measurements) were slightly higher than previous reports $(8,10,21)$. However, a lack of an association between estradiol and random LH, BMI, GR or FAH in our study were in congruent with previous studies $(21,24-26)$. Other studies also demonstrated that estradiol did not relate to BA maturation $(21,25)$.

Interestingly, random LH was elevated during a continuous buserelin infusion, yet the pulsatile fashion was abolished in animal studies $(27,28)$ that resulted in an ineffective sex hormone production. This finding may explain why our patients did not exhibit clinical signs of pubertal progression in response to increased random LH. Moreover, an alteration in the ratio of immunoreactive to bioactive gonadotropins (29) has also been described in patients receiving GnRHa. However, these hypotheses have never been tested in ICPP patients. Further research is needed.

\section{Study limitations}

Our study has some weaknesses. First, we did not regularly assess BA, therefore, we could not evaluate the influence of increased random LH on skeletal maturation. Second, this is a retrospective study, in which we did not evaluate the stimulated LH concentrations at the time of elevated random LH was found. This led to an inability to assess the unknown effect of stimulated LH on GR and FAH. Our study also has a relatively small sample size. However, to our knowledge, this research is the first to demonstrate the longitudinal data of random LH concentrations throughout the treatment duration as well as its association with clinical markers of pubertal progression and FAH.

\section{Conclusion}

In conclusion, we established the longitudinal evidence that random LH is commonly found elevated in ICPP girls during monthly leuprolide treatment. However, the increase in random LH is not associated with clinical progression of puberty nor FAH suggesting this method is unreliable and may not be useful for ICPP monitoring. More studies are needed to evaluate the relationship between elevated basal or stimulated LH and bone age maturation or final adult height.

\section{Acknowledgements}

We gratefully acknowledge the patients and their families. This research was supported by Faculty of Medicine Research Fund, KKU.

\section{Disclosure}

The authors have nothing to disclose.

\section{Author Contribution}

P.W designed the study, performed analytical plan, data analysis, wrote and edited manuscript. O.P. wrote and edited manuscript.

\section{References}

1. Carel JC, Eugster EA, Rogol A, Ghizzoni L, Palmert MR, Antoniazzi F, et al. Consensus statement on the use of gonadotropin-releasing hormone analogs in children. Pediatrics. 2009;123(4):e752-62.

2. Xhrouet-Heinrichs D, Lagrou K, Heinrichs C, Craen M, Dooms L, Malvaux P, et al. Longitudinal study of behavioral and affective patterns in girls with central precocious puberty during long-acting triptorelin therapy. Acta Paediatr. 1997;86(8):808-15.

3. Klein KO, Barnes KM, Jones JV, Feuillan PP, Cutler GB, Jr. Increased final height in precocious puberty after long-term treatment with LHRH agonists: the National Institutes of Health experience. J Clin Endocrinol Metab. 2001;86(10):4711-6.

4. Bereket A. A Critical Appraisal of the Effect of Gonadotropin-Releasing Hormon Analog Treatment on Adult Height of Girls with Central Precocious Puberty. J Clin Res Pediatr Endocrinol. 2017;9(Suppl 2):33-48.

5. Brito VN, Latronico AC, Arnhold IJ, Mendonca BB. A single luteinizing hormone determination 2 hours after depot leuprolide is useful for therapy monitoring of gonadotropindependent precocious puberty in girls. J Clin Endocrinol Metab. 2004;89(9):4338-42. 
6. Lee PA, Neely EK, Fuqua J, Yang D, Larsen LM, Mattia-Goldberg C, et al. Efficacy of Leuprolide Acetate 1-Month Depot for Central Precocious Puberty (CPP): Growth Outcomes During a Prospective, Longitudinal Study. Int J Pediatr Endocrinol. 2011;2011(1):7.

7. Lee PA, Luce M, Bacher P. Monitoring treatment of central precocious puberty using basal luteinizing hormone levels and practical considerations for dosing with a 3-month leuprolide acetate formulation. J Pediatr Endocrinol Metab. 2016;29(11):1249-57.

8. Neely EK, Lee PA, Bloch CA, Larsen L, Yang D, Mattia-Goldberg C, et al. Leuprolide acetate 1-month depot for central precocious puberty: hormonal suppression and recovery. Int $\mathrm{J}$ Pediatr Endocrinol. 2010;2010:398639.

9. Lee PA, Klein K, Mauras N, Lev-Vaisler T, Bacher P. 36-month treatment experience of two doses of leuprolide acetate 3-month depot for children with central precocious puberty. J Clin Endocrinol Metab. 2014;99(9):3153-9.

10. Lewis KA, Eugster EA. Random luteinizing hormone often remains pubertal in children treated with the histrelin implant for central precocious puberty. J Pediatr. 2013;162(3):562-5.

11. Neely EK, Silverman LA, Geffner ME, Danoff TM, Gould E, Thornton PS. Random unstimulated pediatric luteinizing hormone levels are not reliable in the assessment of pubertal suppression during histrelin implant therapy. Int J Pediatr Endocrinol. 2013;2013(1):20.

12. Garibaldi LR, Picco P, Magier S, Chevli R, Aceto T, Jr. Serum luteinizing hormone concentrations, as measured by a sensitive immunoradiometric assay, in children with normal, precocious or delayed pubertal development. J Clin Endocrinol Metab. 1991;72(4):888-98.

13. Brito VN, Batista MC, Borges MF, Latronico AC, Kohek MB, Thirone AC, et al. Diagnostic value of fluorometric assays in the evaluation of precocious puberty. J Clin Endocrinol Metab. 1999;84(10):3539-44.

14. Lee PA. Laboratory monitoring of children with precocious puberty. Arch Pediatr Adolesc Med. 1994;148(4):369-76.

15. Bayley N, Pinneau SR. Tables for predicting adult height from skeletal age: revised for use with the Greulich-Pyle hand standards. J Pediatr. 1952;40(4):423-41.

16. Elmlinger MW, Kuhnel W, Ranke MB. Reference ranges for serum concentrations of lutropin (LH), follitropin (FSH), estradiol (E2), prolactin, progesterone, sex hormone-binding globulin (SHBG), dehydroepiandrosterone sulfate (DHEAS), cortisol and ferritin in neonates, children and young adults. Clin Chem Lab Med. 2002;40(11):1151-60.

17. Lee PA, Klein K, Mauras N, Neely EK, Bloch CA, Larsen L, et al. Efficacy and safety of leuprolide acetate 3-month depot 11.25 milligrams or 30 milligrams for the treatment of central precocious puberty. J Clin Endocrinol Metab. 2012;97(5):1572-80.

18. Liang Y, Wei H, Li J, Hou L, Zhang J, Wu W, et al. Effect of GnRHa $3.75 \mathrm{mg}$

subcutaneously every 6 weeks on adult height in girls with idiopathic central precocious puberty. $\mathrm{J}$ Pediatr Endocrinol Metab. 2015;28(7-8):839-46.

19. Jaruratanasirikul S, Thaiwong M. Outcome of gonadotropin-releasing analog treatment for children with central precocious puberty: 15-year experience in southern Thailand. J Pediatr Endocrinol Metab. 2011;24(7-8):519-23.

20. Houk CP, Kunselman AR, Lee PA. The diagnostic value of a brief GnRH analogue stimulation test in girls with central precocious puberty: a single 30-minute post-stimulation LH sample is adequate. J Pediatr Endocrinol Metab. 2008;21(12):1113-8.

21. Kunz GJ, Sherman TI, Klein KO. Luteinizing hormone (LH) and estradiol suppression and growth in girls with central precocious puberty: is more suppression better? Are pre-injection LH levels useful in monitoring treatment? J Pediatr Endocrinol Metab. 2007;20(11):1189-98.

22. Wacharasindhu S, Sahakitrungrueng T, Supornsilchai V, Bongsebandhu-phubhakdi C. Does GnRH agonist enhance the final adult height in girls with precocious puberty? Asian Biomedicine. 2012;6(5):771-4.

23. Heger S, Partsch CJ, Sippell WG. Long-term outcome after depot gonadotropin-releasing hormone agonist treatment of central precocious puberty: final height, body proportions, body composition, bone mineral density, and reproductive function. J Clin Endocrinol Metab.

1999;84(12):4583-90. 
24. Freire AV, Gryngarten MG, Ballerini MG, Arcari AJ, Escobar ME, Bergada I, et al. Assessment of Estradiol Response after Depot Triptorelin Administration in Girls with Central Precocious Puberty. Horm Res Paediatr. 2016;85(1):58-64.

25. Kobra A. Correlation of Gonadotropins and Estradiol Level 1 Hour after Depot Triptorelin with Clinical Criteria of Adequate Pubertal Suppression in Girls with Central Precocious Puberty. 2017;2(1):5.

26. Carel JC, Lahlou N, Jaramillo O, Montauban V, Teinturier C, Colle M, et al. Treatment of central precocious puberty by subcutaneous injections of leuprorelin 3-month depot $(11.25 \mathrm{mg})$. $\mathrm{J}$ Clin Endocrinol Metab. 2002;87(9):4111-6.

27. McNeilly AS, Fraser HM. Effect of gonadotrophin-releasing hormone agonist-induced suppression of LH and FSH on follicle growth and corpus luteum function in the ewe. J Endocrinol. 1987;115(2):273-82.

28. Gong JG, Campbell BK, Bramley TA, Gutierrez CG, Peters AR, Webb R. Suppression in the secretion of follicle-stimulating hormone and luteinizing hormone, and ovarian follicle development in heifers continuously infused with a gonadotropin-releasing hormone agonist. Biol Reprod. 1996;55(1):68-74.

29. Cedars MI, Surey E, Hamilton F, Lapolt P, Meldrum DR. Leuprolide acetate lowers circulating bioactive luteinizing hormone and testosterone concentrations during ovarian stimulation for oocyte retrieval. Fertil Steril. 1990;53(4):627-31.
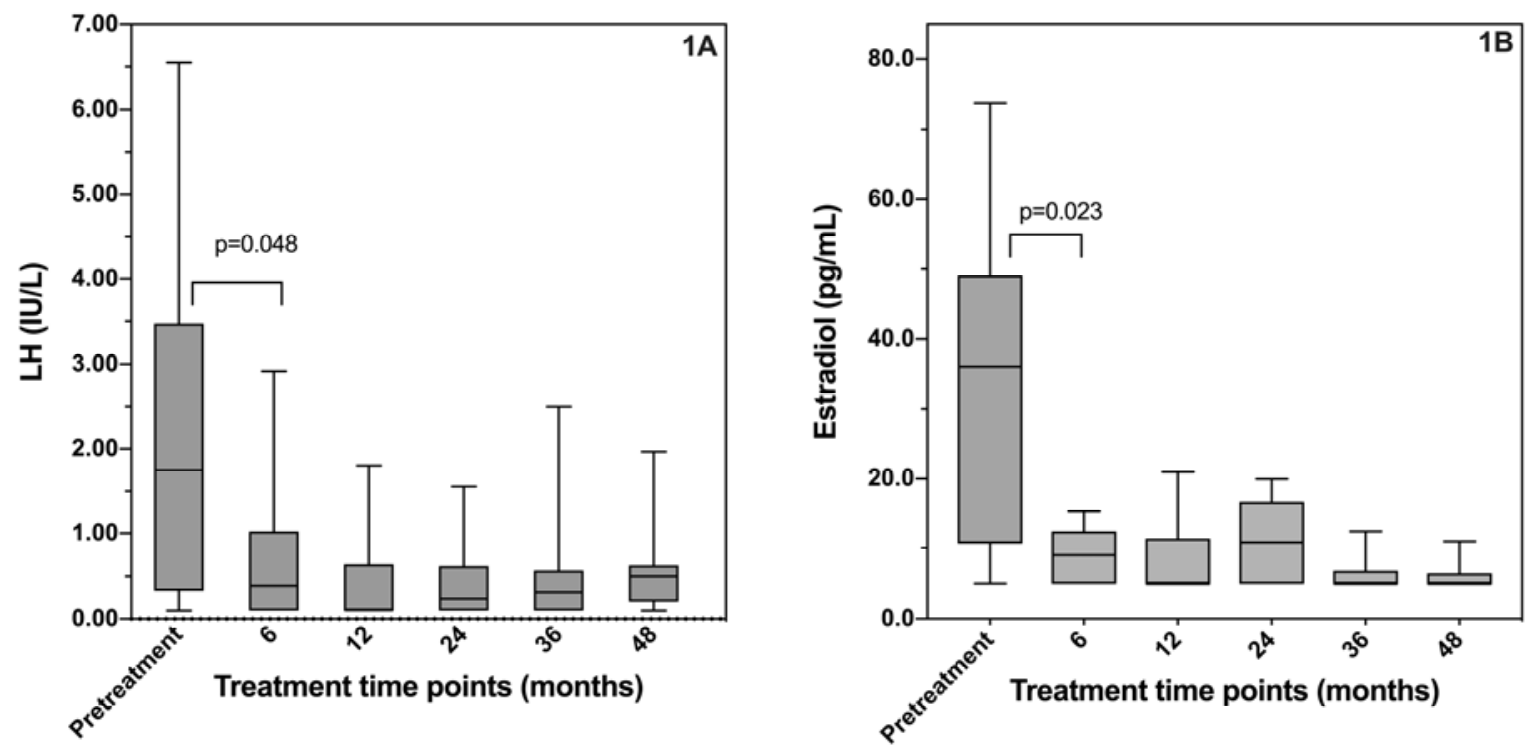

Figure 1. 1A) At month 6, random LH concentrations were significantly lower than pretreatment values $(\mathrm{p}=0.048)$. Thereafter, there were no statistical differences in random LH concentrations between each consecutive time point $(6,12,24,36$ and 48). Random LH concentrations from both IRMA and ICMA at 36 and 48 months of treatment were included for the analysis.

1B) At month 6, serum estradiol concentrations were significantly lower than pretreatment values $(p=0.023)$. There were no statistical differences in serum estradiol concentrations between each consecutive time point (month 6, 12, 24, 36 and 48).

Data are presented as box and whisker plots. The center lines, lower edges and upper edges of the boxes indicate median, 25 th- and 75 th percentiles, respectively. The whiskers indicate 5 th -95 th percentile. 


\begin{tabular}{|l|l|}
\hline \multicolumn{2}{|l|}{ Table 1. Baseline Patient Clinical and Hormonal Characteristics } \\
\hline Characteristics & Patients (N=27) \\
\hline Age of onset, yr. & $6.9 \pm 0.5$ \\
\hline Age of treatment, yr. & $8.1 \pm 0.5$ \\
\hline Bone age (BA), yr. & $11 \pm 0.9$ \\
\hline Height (HT), cm. & $136.3 \pm 6.3$ \\
\hline HT-SDS & $2.3 \pm 1.3$ \\
\hline Weight (WT), kg. & $35.8 \pm 7$ \\
\hline WT-SDS & $3.3 \pm 2$ \\
\hline BMI (kg/m ) & $19.1 \pm 2.8$ \\
\hline BMI-SDS & $1.3 \pm 1.1$ \\
\hline Target height (TH), cm. & $156.0 \pm 4.3$ \\
\hline TH-SDS & $-0.2 \pm 0.9$ \\
\hline Predicted adult height (PAH), cm. & $152.0 \pm 6$ \\
\hline PAH-SDS & $-1 \pm 1.3$ \\
\hline Breast Tanner stage & $3(3,4)$ \\
\hline Pubic Tanner stage & $1(1,2)$ \\
\hline Basal / post-stimulated LH (IU/L) & $1.74(0.33,3.47) / 27(13,64)$ \\
\hline Basal / post-stimulated FSH (IU/L) & $4.2(2.65,5.5) / 15(12.8,18.7)$ \\
\hline Estradiol (pg/mL) & $36(11,53)$ \\
\hline
\end{tabular}

BMI, body mass index; LH, luteinizing hormone; FSH, follicular stimulating hormone Data are presented mean $\pm \mathrm{SD}$, median $(\mathrm{Q} 1, \mathrm{Q} 3)$

Table 2. Final height outcome in 27 girls with ICPP

\begin{tabular}{|c|c|c|c|c|c|}
\hline \multicolumn{3}{|c|}{ Pretreatment } & \multicolumn{3}{|c|}{ Posttreatment } \\
\hline $\begin{array}{l}\text { Height, cm } \\
\text { (SDS) }\end{array}$ & $\begin{array}{l}\text { TH, cm } \\
\text { (SDS) }\end{array}$ & $\begin{array}{l}\text { PAH, cm } \\
\text { (SDS) }\end{array}$ & $\begin{array}{l}\text { FAH, cm } \\
\text { (SDS) }\end{array}$ & $\begin{array}{l}\text { FAH-PAH, cm } \\
\text { (SDS) }\end{array}$ & $\begin{array}{l}\text { FAH-TH, cm } \\
\text { (SDS) }\end{array}$ \\
\hline $\begin{array}{l}136.3 \pm 6.3 \\
(2.3 \pm 1.3)\end{array}$ & $\begin{array}{l}156.0 \pm 4.3 \\
(-0.2 \pm 0.9)\end{array}$ & $\begin{array}{l}152.0 \pm 6 \\
(-1 \pm 1.3)\end{array}$ & $\begin{array}{l}159.5 \pm 5.2^{\mathbf{a}, \mathbf{b}} \\
(0.3 \pm 1)\end{array}$ & $\begin{array}{l}5.9 \pm 6.2 \\
(1.1 \pm 1.3)\end{array}$ & $\begin{array}{l}3.9 \pm 0.9 \\
(0.7 \pm 0.9)\end{array}$ \\
\hline
\end{tabular}

SDS, standard deviation score; TH; target height, $\mathrm{PAH}$; predicted adult height, $\mathrm{FAH}$; final adult height

Data are presented mean $\pm \mathrm{SD}$

${ }^{\mathrm{a}} \mathrm{p}=0.03$ (FAH vs TH)

${ }^{\mathrm{b}} \mathrm{p}<0.0001$ (FAH vs PAH)

Table 3. Correlation analysis between random $\mathrm{LH}$ and estradiol concentrations with growth parameters at corresponding time points

\begin{tabular}{|l|l|}
\hline Parameters & $\begin{array}{l}\text { GR } \\
\text { r (p-value) }\end{array}$ \\
\hline LH (month 12) & $0.286(0.175)$ \\
\hline LH (month 24) & $-0.181(0.419)$ \\
\hline LH (month 36) & $-0.266(0.319)$ \\
\hline LH (month 48) & $-0.734(0.158)$ \\
\hline
\end{tabular}




\begin{tabular}{|l|l|}
\hline Estradiol (month 12) & $-0.102(0.801)$ \\
\hline Estradiol (month 24) & $-0.113(0.887)$ \\
\hline Estradiol (month 36) & $0.323(0.280)$ \\
\hline Estradiol (month 48) & $0.106(0.760)$ \\
\hline
\end{tabular}

LH, luteinizing hormone; GR, growth rate

Data are shown as correlation coefficient (r) and p-value (p) 


\begin{tabular}{|c|c|c|c|c|c|c|c|c|c|c|c|}
\hline \multirow[t]{2}{*}{ No } & \multirow{2}{*}{$\begin{array}{l}\text { CA } \\
\text { (yr) }\end{array}$} & \multirow{2}{*}{$\begin{array}{l}\text { BA } \\
(\mathbf{y r})\end{array}$} & \multirow{2}{*}{$\begin{array}{l}\text { TH } \\
\text { (cm) }\end{array}$} & \multirow{2}{*}{$\begin{array}{l}\text { PAH } \\
(\mathbf{c m})\end{array}$} & \multirow{2}{*}{$\begin{array}{l}\text { FAH } \\
\text { (cm) }\end{array}$} & \multirow{2}{*}{$\begin{array}{l}\text { Treatment } \\
\text { Duration } \\
\text { (yr) }\end{array}$} & \multicolumn{5}{|c|}{ Random LH levels (IU/L) } \\
\hline & & & & & & & $6 \mathrm{~m}$ & $1 \mathrm{y}$ & $2 y$ & $3 y$ & $4 y$ \\
\hline 1 & 7.8 & 12.5 & 158.0 & 150.4 & 158 & 4.6 & 2.9 & 0.1 & 0.2 & 1.06 & 2.0 \\
\hline 2 & 6.9 & 12.5 & 156.0 & 151.5 & 162 & 4.9 & 0.1 & 0.1 & 1.1 & 2.5 & 0.62 \\
\hline 3 & 7 & 12 & 156.0 & 153.7 & 162 & 4.8 & 0.9 & - & 0.98 & 2.4 & $0.60^{*}$ \\
\hline
\end{tabular}

CA, chronological age at treatment start; BA, bone age at treatment start; TH, target height; PAH, predicted adult height; FAH, final adult height; LH, luteinizing hormone * indicates random LH from ICMA 